\title{
Linear Trend Application on the Estimated Age of Distribution Transformer Based on the Load Growth and Environmental Temperature
}

\author{
Fadly Azhar ${ }^{1}$, Yuni Rahmawati ${ }^{1}$, Irham Fadlika ${ }^{1,2}$
}

\author{
Authors \\ ${ }^{1}$ Department of Electrical Engineering Universitas Negeri \\ Malang, Indonesia.
}

${ }^{2}$ Smart Power and Advanced Enegy Systems Research Center, Jawa Timur, Indonesia

Corresponding:fadlyazhar12@gmail.com

\begin{abstract}
This research aimed to find the age loss of distribution transformer based on the load growth and ambient temperature to predict the remaining age of the transformer. This research used the remaining estimation age calculation based on load growth that was predicted using the linear trend analysis. The distribution transformer in this research was the BO043 $200 \mathrm{kVA}$, installed in 2012, and was operated in Bolo Feeder, Woha District, Bima Regency. The results showed that the BO043 transformer was operating at the average ambient temperature of $28^{\circ} \mathrm{C}$ with the optimum loading threshold of $92.77 \%$ from its power rating. The transformer would experience age reduction if the load given were above that value. The calculation results showed that the BO043 transformer had the estimated remaining age of 4 years from the standard 23 years with the 2019 load prediction of $83.39 \%$ and up to $115.94 \%$ load prediction in 2022 .
\end{abstract}

Keywords

transformer age, linear trend, load growth, ambient temperature

\section{Introduction}

A transformer is an expensive device, thus requires intensive maintenance, so the device has a long operating life. Many factors influence the distribution transformer condition. A cause for damaging or reducing the age is the load. The increasing utilisation of electricity by consumers causes load growth in the transformer [1]-[3]. The continuous load growth causes overload. Overload is when the load value exceeds the transformer rating capacity. Overload causes temperature growth in the transformer. The emerged heat causes disintegration from the transformer materials and accelerates the ageing of a transformer.

In its 60076-7 2005 publication, the IEC set the average transformer age that is 30 years with $100 \%$ load from its rating at around $20^{\circ} \mathrm{C}$ temperature and resulted in a hotspot temperature of $98^{\circ} \mathrm{C}$. Meanwhile, according to the standard of the IEEE C.57.91 1999, the average transformer age is 20.55 years, operating at around $30^{\circ} \mathrm{C}$ temperature with hotspot threshold up to $110^{\circ} \mathrm{C}$. Other than the load, ambient temperature also influences the transformer's hotspot [1], [4], [5]. Higher temperature means higher hotspot that creates heat in the transformer.

Based on the observation in Woha District, several transformers in Bolo Feeder experienced significant load growth in a particular period. One being BO043 transformer with significant load growth of $60.41 \%$ load peak in the first period of 2017 and significantly increased to $80.60 \%$ in the fourth period of 2018 . The unstable load and ambient temperature affect the transformer age. Therefore, it is vital to know the age loss of a transformer due to load growth and ambient temperature because it helps in predicting the remaining age.

\section{Main Current Research}

\section{A. Distribution Transformer}

A distribution transformer is an essential device in the distribution system [1], [6], [7]. It functions as a converter for the $20 \mathrm{kV}$ medium voltage from SUTM into 400/230 V low voltage with the operating voltage of $380 / 220 \mathrm{~V}$.

\section{B. Linear Trend Analysis}

The linear trend analysis is an analysis of time series data which resulted in the form of a trend equation that can be used for future forecasting [3], [4], [8]. Below is the linear trend equation to predict the transformer's load. 
$Y_{t}=a+b X_{t}$

Note: $\quad Y_{t}=$ Load at t-time

$X_{t}=$ Period at t-time

$a=$ constant

$b=$ coefficient

Determining the value of $a$ constant and $b$ coefficient use Equation (2) and Equation (3).

$$
\begin{aligned}
& b=\frac{(n)\left(\sum X Y\right)-\left(\sum X\right)\left(\sum Y\right)}{(n)\left(\sum X^{2}\right)-\left(\sum X\right)^{2}} \\
& a=\frac{\left(\sum Y\right)}{n}-b \frac{\left(\sum X\right)}{n}
\end{aligned}
$$

Note: $\quad \sum X=$ Amount of data retrieval per 3 months

$\sum Y=$ Total load in transformer

$n=$ Amount of $\mathrm{X}$ and $\mathrm{Y}$ variables

\section{Transformer Temperature}

A factor that influences a transformer's temperature is the hotspot [9]-[14]. A hotspot is the hottest part of a transformer and occurs on the transformer windings. The ambient temperature determines the change in hotspot temperature. Higher ambient temperature means higher hotspot, and vice versa. The amount of load in a transformer also determines the temperature growth of the transformer. As a guide on calculating the load, Table I presents the thermal characteristics of the ONAN refrigerant type distribution transformer.

TABLE I

THERMAL CHARACTERISTICS OF ONAN REFRIGERANT DISTRIBUTION TRANSFORMERS ACCORDING TO IEC 60076-2

\begin{tabular}{|c|c|}
\hline Transformer Thermal Characteristic & ONAN Distribution Transformer \\
\hline Oil Exponent (x) & 0.8 \\
\hline Winding Exponent (y) & 1.6 \\
\hline Loss Ratio (R) & 23 \\
\hline $\begin{array}{c}\text { The hot spot gradient to the top oil (in the } \\
\text { tank) in the rated current (Hgr) }\end{array}$ & 55 \\
\hline $\begin{array}{c}\text { An increase in the temperature of the top oil ( } \\
\left.\Delta \theta_{o r}\right)\end{array}$ & 5 \\
\hline
\end{tabular}

The transformer's hotspot temperature can be calculated using Equation (4).

$\theta_{h}=\theta_{a}+\Delta \theta_{o r}\left(\frac{1+R K^{2}}{1+R}\right)^{x}+H g_{r} \cdot K^{y}$

Note: $\theta_{h}=$ Hotspot temperature $\left({ }^{\circ} \mathrm{C}\right), \theta_{a}=$ Ambient temperature $\left({ }^{\circ} \mathrm{C}\right), \Delta \theta_{\text {or }}=$ Temperature growth of the top oil, $R=$ Loss ratio, $K=$ Load ratio, $x=$ Oil exponent, $y=$ Winding exponent, $H g_{r}=$ the hot spot gradient to the top oil at rated current.

\section{Transformer Age}

According to the International Electrotechnical Commission (IEC), if a transformer is given the maximum load (100\%) from its capacity, it will have 30 years of operation life at $20^{\circ} \mathrm{C}$ ambient temperature. The decrease in the transformer's age depends on the temperature. Around the $80^{\circ}-140^{\circ} \mathrm{C}$, the rate of aging of the transformer doubles for each $6^{\circ} \mathrm{C}$ increase of hot spot temperature. The loss of age due to hotspot temperature can be seen in Table II. 
TABLE II

AgE LOSS DUE TO TEMPERATURE GROWTH ACCORDING TO IEC 60354

\begin{tabular}{|l|l|l|l|l|l|l|l|l|l|l|l|}
\hline Hot Spot $\left({ }^{\circ} \mathrm{C}\right)$ & 80 & 86 & 92 & 98 & 104 & 110 & 116 & 122 & 128 & 134 & 140 \\
\hline Age loss (p.u) & 0.125 & 0.25 & 0.5 & 1 & 2 & 4 & 8 & 16 & 32 & 64 & 128 \\
\hline
\end{tabular}

The ageing factor or ageing rate of the transformer at each increase in hotspot temperature above the average temperature $\left(98^{\circ} \mathrm{C}\right)$ can be calculated using Equation (5).

$$
V=2^{\left(\frac{\theta_{h}-98^{\circ} \mathrm{C}}{6}\right)}
$$

Note: $V=$ the relative value of service life, $\theta_{h}=$ hotspot temperature $\left({ }^{\circ} \mathrm{C}\right)$

Age loss can be stated in a month, day, or hourly unit if the load and ambient temperature are constant in a period. The relative age loss of a transformer in one period can be calculated using Equation (6).

$$
L=\frac{(V 1 . t 1)+(V 2 . t 2)+\ldots(V n . t n)}{T} \times 100 \%
$$

Note: $L=$ Age loss, $T=$ Time, $V=$ Relative ageing rate, $t=$ time interval

Calculating the predicted remaining transformer's age uses Equation (7).

Transformer remaining age $=\frac{\text { Basic age }-n}{L}$

Note: Basic age $=30$ years, $n=$ transformer's operation duration (years)

\section{Method}

This research used a calculation method based on daily load and prediction load with the linear trend analysis to calculate the estimated remaining age of the transformer. The research object was the BO043 200 $\mathrm{kVA}$ transformer, installed in 2012, that operated in Bolo Feeder, Woha District, Bima Regency. Below is the flowchart to estimate the remaining age of the transformer using the linear trend analysis.

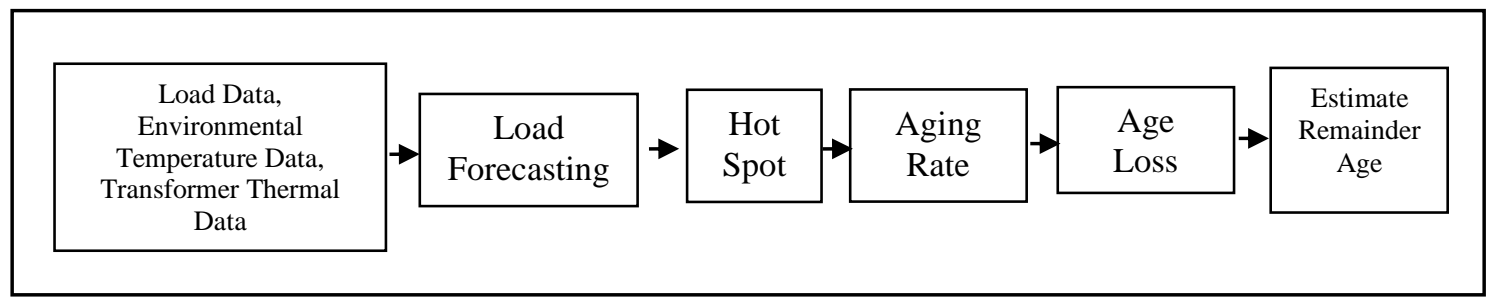

Fig. 1. Calculation Flow Chart

\section{Result}

Below is the calculation of the estimated remaining age of BO043 transformer based on the load data of 28 September 2018 using Equation (4) to Equation (7). 
TABLE III

CALCUlation Result FOR BO043 Transformer Age Estimation BASEd On LOADING ON 28 SEPTEMBER 2018

\begin{tabular}{|c|c|c|c|c|c|c|}
\hline Time & $\begin{array}{c}\text { Transformer } \\
\text { Load }(\%)\end{array}$ & $\begin{array}{c}\text { Ambient } \\
\text { Temperature } \\
\left({ }^{\circ} \mathrm{C}\right)\end{array}$ & $\begin{array}{l}\text { Hot } \\
\text { Spot } \\
\left({ }^{\circ} \mathrm{C}\right)\end{array}$ & $\begin{array}{l}\text { Ageing } \\
\text { Rate } \\
\text { (p.u) }\end{array}$ & $\begin{array}{c}\text { Daily Age } \\
\text { Loss } \\
(\%)\end{array}$ & $\begin{array}{c}\text { Age } \\
\text { Remaining } \\
\text { Estimation } \\
\text { (Tahun) }\end{array}$ \\
\hline 02.00 & 60.74 & 24 & 63.48 & 0.0185 & \multirow{12}{*}{8.45} & \multirow{12}{*}{$\geq 23$} \\
\hline 04.00 & 61.33 & 25 & 64.97 & 0.0220 & & \\
\hline 06.00 & 63.06 & 26 & 67.4 & 0.0292 & & \\
\hline 08.00 & 66.41 & 28 & 72.26 & 0.0511 & & \\
\hline 10.00 & 65.13 & 31 & 74.16 & 0.0637 & & \\
\hline 12.00 & 68.26 & 32.8 & 78.68 & 0.1073 & & \\
\hline 14.00 & 70.80 & 31 & 79.16 & 0.1134 & & \\
\hline 16.00 & 71.71 & 29 & 77.98 & 0.0990 & & \\
\hline 18.00 & 78.75 & 27 & 82.62 & 0.1692 & & \\
\hline 20.00 & 81.63 & 26 & 84.45 & 0.2090 & & \\
\hline 22.00 & 76.56 & 25 & 78.51 & 0.1052 & & \\
\hline 24.00 & 64.33 & 24 & 66.48 & 0.0262 & & \\
\hline
\end{tabular}

Based on the above calculation, the load and hotspot temperature are still below the threshold, does not exceed the ideal load threshold, and follows the SPLN standardization that is $80 \%$, and does not exceed the safe hotspot threshold according to the IEC $600767-7$ that is $98^{\circ} \mathrm{C}$. The highest hotspot temperature occurred at $84.45^{\circ} \mathrm{C}$. The transformer will experience age loss if the hotspot temperature is above $98^{\circ} \mathrm{C}$ for 24 hours or daily age loss above $100 \%$. Therefore, BO043 transformer did not experience age loss. This transformer was operated since 2012, or for seven years now. To date, it was in a normal condition. Using the load condition on 28 September 2018, the transformer's remaining age is similar to the average remaining age of 23 years. The load history data every three months in Table IV shows that the transformer experienced load growth. Thus, the calculation of the remaining age was performed.

TABLE IV

BO043 TRANSFormer LOADING DATA PER 3 MONTHS

\begin{tabular}{|c|c|c|c|}
\hline \multirow{2}{*}{ Year } & \multirow{2}{*}{ Period } & \multicolumn{2}{|c|}{ Transformer Load } \\
\cline { 2 - 4 } & & KVA & $(\%)$ \\
\hline \multirow{3}{*}{2017} & 1 & 120.81 & 60.41 \\
\cline { 2 - 4 } & 2 & 130.98 & 65.49 \\
\cline { 2 - 4 } & 3 & 144.61 & 72.30 \\
\cline { 2 - 4 } & 4 & 144.61 & 72.30 \\
\hline \multirow{3}{*}{2018} & 1 & 143.45 & 71.73 \\
\cline { 2 - 4 } & 2 & 157.08 & 78.54 \\
\cline { 2 - 4 } & 3 & 151.31 & 75.65 \\
\cline { 2 - 4 } & 4 & 161.20 & 80.60 \\
\hline
\end{tabular}

This study obtained the linear trend equation to predict the transformer's load using Equation (1) to Equation (3) that was $\mathrm{Y}=60.86+2.50 \mathrm{X}$. After manually calculated the constant and coefficient, next, the correctness test was conducted. Below are the prediction load results using the Minitab software and the transformer's age estimation using Equation (4) to Equation (7). Table V shows that every three months, there was a significant load growth that caused the hotspot temperature growth. The higher hotspot temperature means more considerable age loss in the transformer and causes the transformer's age to experience significant loss.

The transformer had been operated since 2012 or for seven years. According to the IEC 60076-7 2005 standard, the remaining average age is 23 years. The transformer will operate until 2042 with the maximum load $(100 \%)$, at around $20^{\circ} \mathrm{C}$ temperature with a hotspot temperature of $98^{\circ} \mathrm{C}$. Because the transformer 
operated in the ambient temperature of around $28^{\circ} \mathrm{C}$, following the calculation in this research, the hotspot would reach $98^{\circ} \mathrm{C}$ at $92.77 \%$ load. In other words, the transformer would operate at an average operational age if it did not get the load above $92.77 \%$. The load growth of BO043 transformer that increases every three months will affect the age loss and reduce the remaining age, as shown in Figure 2.

TABLE V

CALCUlation Result For BO043 TRANSFORMER Age Estimation Using LinEAR TREND

\begin{tabular}{|c|c|c|c|c|c|c|c|}
\hline Year & $\begin{array}{c}\text { Period } \\
(\mathrm{X})\end{array}$ & $\begin{array}{l}\text { Load } \\
\text { Prediction } \\
\text { (Y) } \\
(\%)\end{array}$ & $\begin{array}{c}\text { Winding } \\
\text { Temperature } \\
\left({ }^{\circ} \mathrm{C}\right)\end{array}$ & $\begin{array}{l}\text { Ageing } \\
\text { Rate } \\
\text { (p.u) }\end{array}$ & $\begin{array}{c}\text { Age } \\
\text { Loss/Day } \\
(\%)\end{array}$ & $\begin{array}{l}\text { Remaining } \\
\text { Age } \\
\text { Estimation } \\
\text { (Year) }\end{array}$ & $\begin{array}{l}\text { Normal } \\
\text { Remaining } \\
\text { Age } \\
\text { (Year) }\end{array}$ \\
\hline \multirow{4}{*}{2019} & 9 & 83.39 & 88.21 & 0.323 & 32.27 & $\geq 23$ & \multirow{4}{*}{23} \\
\hline & 10 & 85.90 & 90.76 & 0.433 & 43.33 & $\geq 23$ & \\
\hline & 11 & 88.40 & 93.36 & 0.585 & 58.51 & $\geq 23$ & \\
\hline & 12 & 90.90 & 96.00 & 0.794 & 79.37 & $\geq 23$ & \\
\hline \multirow{4}{*}{2020} & 13 & 93.41 & 98.69 & 1.083 & 108.30 & 20.3 & \multirow{4}{*}{22} \\
\hline & 14 & 95.91 & 101.43 & 1.486 & 148.62 & 14.8 & \\
\hline & 15 & 98.41 & 104.21 & 2.049 & 204.91 & 10.7 & \\
\hline & 16 & 100.92 & 107.04 & 2.842 & 284.15 & 7.7 & \\
\hline \multirow{4}{*}{2021} & 17 & 103.42 & 109.91 & 3.959 & 395.86 & 5.3 & \multirow{4}{*}{21} \\
\hline & 18 & 105.92 & 112.83 & 5.547 & 554.68 & 3.7 & \\
\hline & 19 & 108.43 & 115.79 & 7.808 & 780.83 & 2.6 & \\
\hline & 20 & 110.93 & 118.80 & 11.05 & 1105.53 & 1.9 & \\
\hline \multirow{2}{*}{2022} & 21 & 113.43 & 121.85 & 15.725 & 1572.51 & 1.2 & \multirow{2}{*}{20} \\
\hline & 22 & 115.94 & 124.94 & 22.471 & 2247.11 & $<1$ & \\
\hline
\end{tabular}

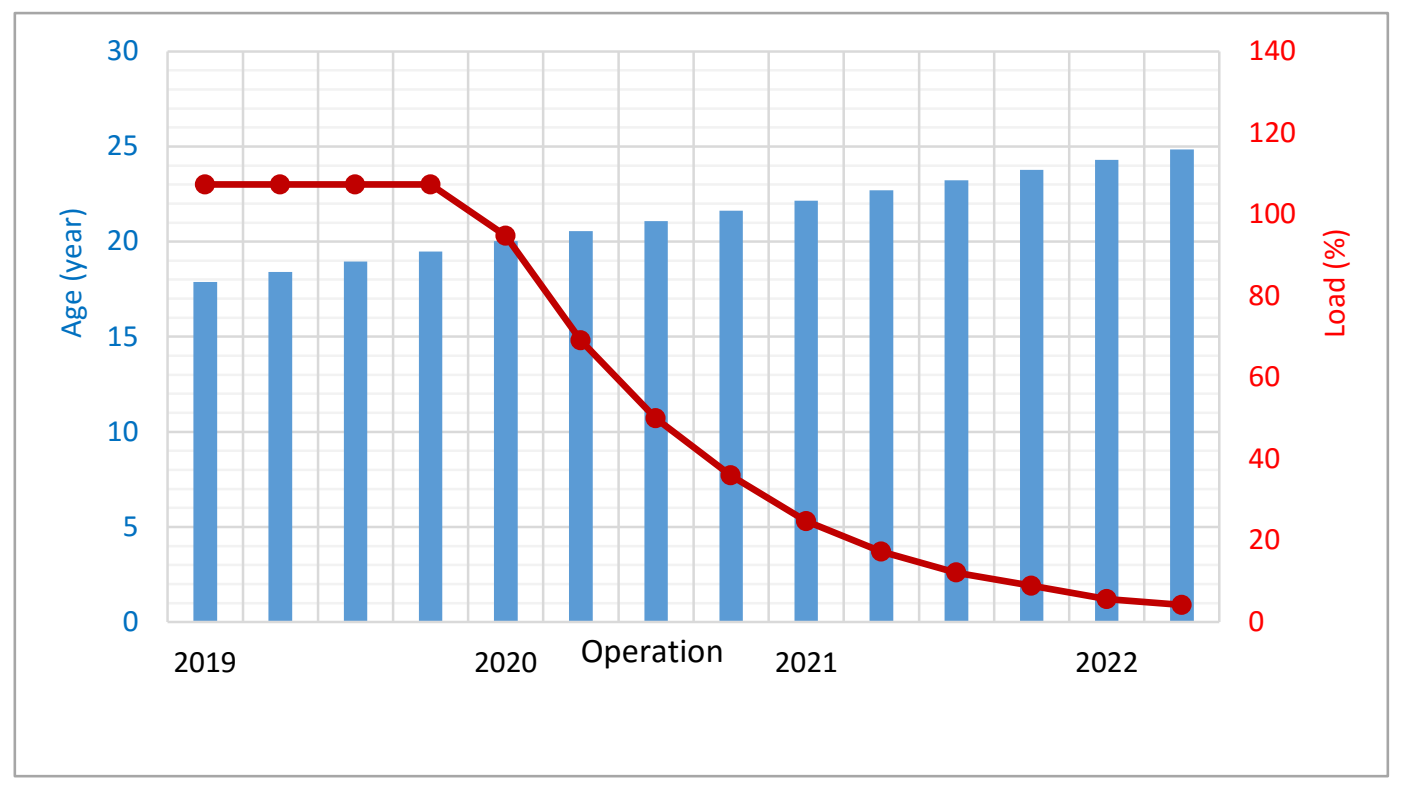

Fig. 2. Load and Forecast Lifespan Transformer BO043

In 2019 prediction, the transformer reaches up to $90.90 \%$ load with $96^{\circ} \mathrm{C}$ hotspot and the estimated remaining age above or similar with the average remaining age of 23 years. In other words, the transformer has yet to experience age loss because the load is still below the optimum load $(92.77 \%)$, and it will operate below the safe hotspot temperature $\left(98^{\circ} \mathrm{C}\right)$. The significant load growth causes the transformer to overload in 2020 with load value up to $100.92 \%$ and hotspot above the standard that is $107.04^{\circ} \mathrm{C}$. As a result, the estimated remaining age becomes 7.7 years. The overload in the transformer increases until 2022 at $115.94 \%$ with hotspot temperature of $124.94^{\circ} \mathrm{C}$, causing the age to decrease drastically, and the remaining age is estimated to be less than one year. 


\section{Conclusion}

The research showed that BO043 transformer that operated in the ambient temperature of $28^{\circ} \mathrm{C}$ should not be given load above $92.77 \%$ of its power rating because it caused age loss. The results showed that the load on 28 September 2018 stated that the transformer was still in reasonable condition and had the remaining age above of the same with the average remaining age, or 23 years. The results that used linear trend analysis showed that the transformer had the remaining age of 4 years out of the typical age of 23 years.

\section{Acknowledgment}

We are grateful to the PLN Woha District for giving permission and research assistance.

\section{References}

[1] B. Trkulja, A. Drandić, and Ž. Štih, "Development of 3D BEM code for Computation of a Transformer Winding's Capacitance Matrix," Procedia Eng., vol. 202, pp. 327-332, 2017, doi: 10.1016/j.proeng.2017.09.721.

[2] B. Bosnjak, G. Leber, and H. Landes, "Coupled 3D Transient Magneto-Mechanical FEM Simulation of a Short Circuit Test on a Mock-up of a 570 MVA Transformer Unit,” Procedia Eng., vol. 202, pp. 224-230, 2017, doi: 10.1016/j.proeng.2017.09.709.

[3] F. Lv, H. Du, H. Sun, Z. Wang, and Y. Li, "Power Transformer Fault Diagnosis Based on Data Fusion," IFAC Proc. Vol., vol. 41, no. 2, pp. 11013-11017, 2008, doi: 10.3182/20080706-5-KR1001.01865 .

[4] H. Chandra, "Microprocessor Based Thermal Model Approach For Protection And Optimum Utilisation of Power Thyristors Transformers And Drives," in TENCON '91. Region 10 International Conference on EC3-Energy, Computer, Communication and Control Systems, New Delhi, India, 1991, vol. 1, pp. 251-255, doi: 10.1109/TENCON.1991.712559.

[5] X. Wang, Y. Cui, G. Wu, Q. Peng, L. Chen, and Z. Duan, "Influence of acid on frequency domain dielectric spectroscopy of oil-paper insulation," in 2013 Annual Report Conference on Electrical Insulation and Dielectric Phenomena, Chenzhen, China, 2013, pp. 65-68, doi: 10.1109/CEIDP.2013.6748194.

[6] H. Açıkgöz, Ö. F. Keçecioğlu, A. Gani, C. Yıldız, and M. Şekkeli, "Optimal Control and Analysis of Three Phase Electronic Power Transformers," Procedia - Soc. Behav. Sci., vol. 195, pp. 2412-2420, Jul. 2015, doi: 10.1016/j.sbspro.2015.06.240.

[7] J. C. Yeh, C. E. Lin, C. L. Huang, and C. L. Cheng, "Calculation and harmonic analysis of transient inrush currents in three-phase transformers," Electr. Power Syst. Res., vol. 30, no. 2, pp. 93-102, Jul. 1994, doi: 10.1016/0378-7796(94)90003-5.

[8] N. Greco, A. Parisi, N. Spina, E. Ragonese, and G. Palmisano, "Scalable lumped models of integrated transformers for galvanically isolated power transfer systems," Integration, vol. 63, pp. 323-331, Sep. 2018, doi: 10.1016/j.vlsi.2018.01.005.

[9] L. Raeisian, H. Niazmand, E. Ebrahimnia-Bajestan, and P. Werle, "Thermal management of a distribution transformer: An optimization study of the cooling system using CFD and response surface methodology," Int. J. Electr. Power Energy Syst., vol. 104, pp. 443-455, Jan. 2019, doi: 10.1016/j.ijepes.2018.07.043.

[10] L. Raeisian, H. Niazmand, E. Ebrahimnia-Bajestan, and P. Werle, "Feasibility study of waste vegetable oil as an alternative cooling medium in transformers," Appl. Therm. Eng., vol. 151, pp. 308-317, Mar. 2019, doi: 10.1016/j.applthermaleng.2019.02.010.

[11] T. Mariprasath and V. Kirubakaran, "A real time study on condition monitoring of distribution transformer using thermal imager," Infrared Phys. Technol., vol. 90, pp. 78-86, May 2018, doi: 10.1016/j.infrared.2018.02.009.

[12] R. M. Arias Velásquez and J. V. Mejía Lara, "Explosion of power capacitors in a change of transformers with reactive power compensation," Eng. Fail. Anal., vol. 106, p. 104181, Dec. 2019, doi: 10.1016/j.engfailanal.2019.104181.

[13] X. Zhang, M. Daghrah, Z. Wang, and Q. Liu, "Flow and temperature distributions in a disc type winding-Part II: Natural cooling modes," Appl. Therm. Eng., vol. 165, p. 114616, Jan. 2020, doi: 10.1016/j.applthermaleng.2019.114616.

[14] R. Sitar, I. Śulc, and Ž. Janić, "Prediction of local temperature rise in power transformer tank by FEM,” Procedia Eng., vol. 202, pp. 231-239, 2017, doi: 10.1016/j.proeng.2017.09.710. 